Review

\title{
Application of Pyrolysis Gas Chromatography/Mass Spectrometry in Lacquer Research: A Review
}

\author{
Xiao-Ming Ma, Rong Lu * and Tetsuo Miyakoshi \\ Department of Applied Chemistry, School of Science and Technology, Meiji University, \\ 1-1-1 Higashi-mita, Tama-ku, Kawasaki-shi 214-8571, Japan; \\ E-Mails:mxm0315@yahoo.co.jp (X.-M.M.); miya@isc.meiji.ac.jp (T.M.) \\ * Author to whom correspondence should be addressed; E-Mail: lurong@isc.meiji.ac.jp; \\ Tel./Fax: +81-44-9347784.
}

Received: 5 December 2013; in revised form: 4 January 2014 / Accepted: 7 January 2014 / Published: 10 January 2014

\begin{abstract}
Examination of thermal degradation of natural and synthetic lacquer films by pyrolysis-gas chromatography with mass spectrometry (Py-GC/MS) is reviewed. Due to the instantaneous heating decomposition, side reactions of internal or intermediate samples hardly occur, and the pyrolysis products can be retrieved without any change. Py-GC/MS has been used to analyze the composition of insoluble polymers and investigate degradation of resin materials. Lacquer film is a cross-linked polymer that is insoluble in any solvent. The aim of this review is to describe the application of Py-GC/MS to the analysis of lacquer, including natural lacquer saps, synthetic lacquer derivatives, and their films. After analyzing the chemical structures of the specific pyrolysis products by mass spectrometry, the lacquer tree species and growing region can be determined. These results have great significance for the protection and restoration of lacquer-coated cultural treasures.
\end{abstract}

Keywords: Py-GC/MS; lacquer film; composition analysis; chemical structure

\section{Introduction}

The Asian lacquer known as Shengqi, in China, and Urushi, in Japan, is sap collected from Rhus vernicifera lacquer trees, and the main lipid component is urushiol. Vietnamese and Chinese Taiwan lacquer is sap from Rhus succedanea trees, and the main lipid component is laccol. Myanmar, Laos, Cambodia, and Thailand lacquer is sap from Melanorrhonea (Gluta) usitata trees, and the main 
lipid component is thitsiol. All three lipid components are composed mainly of substituted catechols in the 3- or 4-position that have long unsaturated side chains with 1-3 olefins. These saps have been utilized for coating materials because of their particular beauty and high durability.

Lacquer wares have been used and valued highly due to their toughness and beauty for a long time. In recent years, interest in the use of renewable resources in the production of various industrial materials has been revived because of environmental concerns. Lacquer is dried in natural conditions: first, the lipid component is oxidized by laccase, and subsequent autoxidation of the unsaturated side chains occurs in the open air. Research on lacquer chemistry can be traced back to 1878 [1], and the combination of pyrolysis with gas chromatography (Py-GC) and/or mass spectrometry also has been reported for nearly 60 years. In 1983, Burmester [2] first reported a classification of far eastern lacquer by using pyrolysis combined with mass spectrometry (Py-MS). In 1989, Shedrinsky [3] reported the application of Py-GC to art and archaeology.

However, due to the complex chemical and physical features of the polymeric lacquer film, the analyses were not satisfactory. After doing a full literature review, we believe that the first successful use of pyrolysis-gas chromatography with mass spectrometry (Py-GC/MS) to analyze lacquer films was reported by Niimura et al. in 1995 [4]. They used urushiol, plant gum, and glycoproteins isolated from the same lacquer sap as a control to study the pyrolytic behavior of lacquer film. Although the pyrolysis produced a very complex pyrogram, almost all peaks were assigned according to the mass spectrometry analysis. Subsequently, the authors reported the characterization of laccol [5] and thitsiol [6] lacquer films by Py-GC/MS, and alkenes, alkanes, alkenylphenols, alkylphenols, alkenylbenzenes, and alkylbenzenes were detected. In order to clearly distinguish the characteristic pyrolysis products of lacquer film, urushiol, laccol, and thitsiol derivatives were synthesized, and the synthesized lacquer films were compared with the natural lacquer. In addition, we will discuss the application of Py-GC/MS to the important traditional lacquer wares, our experiences using this method, as well as how to effectively use and improve this method in studies of lacquer chemistry.

\section{Pyrolysis-Gas Chromatography/Mass Spectrometry}

Py-GC/MS is a method of chemical analysis that first thermally degrades the sample to produce smaller and more analytically useful fragments that can be separated on a GC column and detected in an MS instrument (Figure 1). As Py-GC/MS decomposes instantly, aggregates of pyrolysates and other side products rarely occur. Thus, chemically unchanged pyrolysates can be examined. Py-GC/MS can be used to examine the composition of polymer materials that are difficult to dissolve in a solvent, investigate resin deterioration, and analyze volatile additives. It is useful for polymers, polymer blends, and copolymers that are difficult to analyze by other methods. However, as many specimens cannot be fitted into the sample tube, it is difficult to analyze trace components. The history and scope of Py-GC and Py-MS have been reviewed by Wampler [7], Sobeih [8], and Tsuge [9]. This review is mainly focused on its use in lacquer chemistry. 
Figure 1. Configuration of Py-GC/MS system.

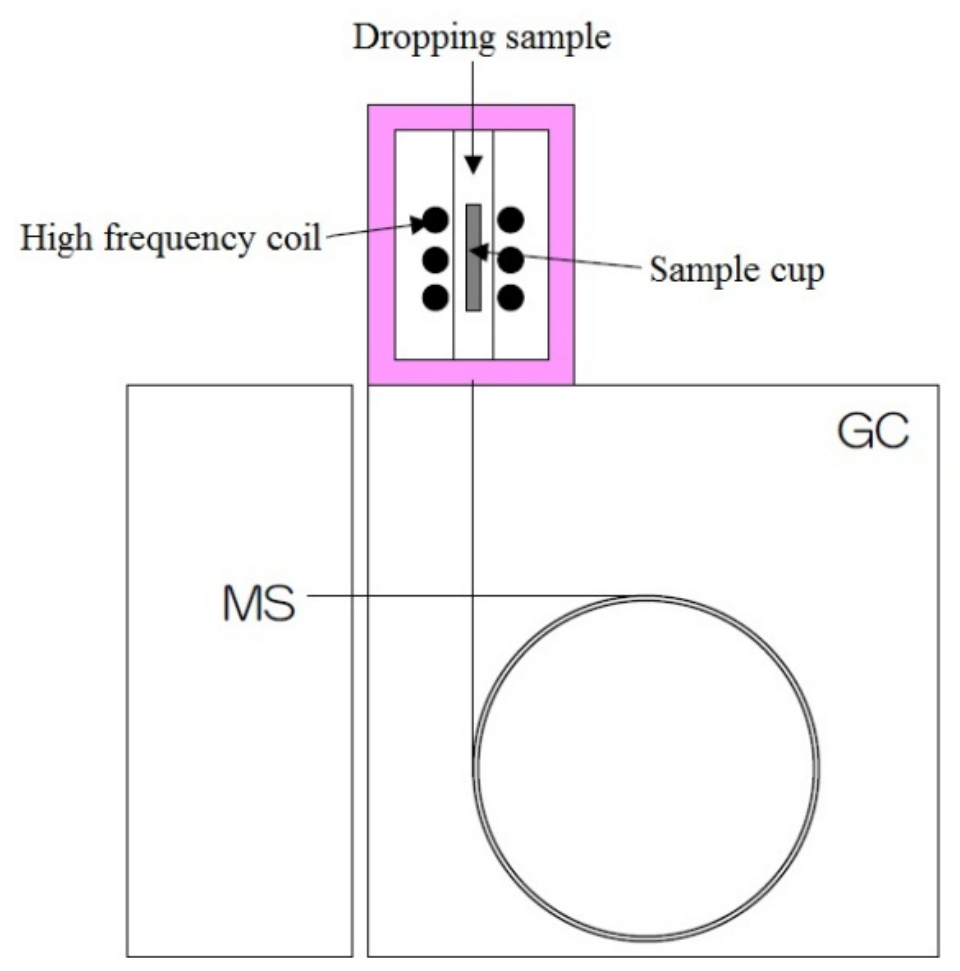

The analysis method involves putting the sample in the inactivated sample holder of the microfurnace, dropping the sample holder into the reactor core, which is wrapped with high frequency coils, and filled with helium as the carrier gas using a switch, and then pyrolyzing it. The pyrolysis results are rather stable due to the comparatively low dispersion temperature changes due to the sample holder's small capacity [10].

\subsection{Single-Shot Py-GC/MS}

The simplest Py-GC/MS, called single shot, is a method in which only one heating accomplishes the thermal decomposition. The range of temperatures for thermal decomposition is $50-1000{ }^{\circ} \mathrm{C}$. After thermal decomposition, the sample is vaporized and introduced into a gas chromatograph. The gas is separated by GC and measured by MS. The advantage of this technique is being able to analyze all components in the original sample in one measurement. This means that the ratio of components in the original solid can be determined. In the case of lacquer, the decomposition temperature is $500{ }^{\circ} \mathrm{C}$ and dimethyl polysiloxane or phenyl methylpolysiloxane type GC column was employed. As lacquer film has a catechol configuration, its polarity is very high. Therefore, if a very polar column is used, detection will decrease. Moreover, setting the temperature of the oven high enough and using a heat-resistant column are also important because urushiol is undetectable at temperatures lower than $280{ }^{\circ} \mathrm{C}$.

\subsection{Evolved Gas Analysis}

Evolved gas analysis (EGA) is a method used to analyze the gas emitted while the heated sample undergoes decomposition or desorption [11-14]. The mechanical configuration characteristically uses a short column and evolved gas detection (EGD). As many organic macromolecules are decomposed at 
less than $1000{ }^{\circ} \mathrm{C}$, a restricted set of temperatures in the range of $50-1000{ }^{\circ} \mathrm{C}$ is used. In the research on lacquer films, the temperature range is always set at $50-650{ }^{\circ} \mathrm{C}$, and the gas chromatograph oven was programmed to provide a constant temperature increase of $10{ }^{\circ} \mathrm{C}$ per min, from 50 to $650{ }^{\circ} \mathrm{C}$. EGA analysis decomposes a lacquer film in three steps: low $\left(100-200{ }^{\circ} \mathrm{C}\right)$, medium $\left(200-300{ }^{\circ} \mathrm{C}\right)$, and high $\left(300-500{ }^{\circ} \mathrm{C}\right)$ temperature from our results as shown in Figure 2. The first peak of $\mathrm{m} / \mathrm{z}=60$ at the low temperature $\left(100-200^{\circ} \mathrm{C}\right)$ was short carboxylic acid with various carbon chains. The second peak at the medium $\left(200-300^{\circ} \mathrm{C}\right)$ was considered to be due to the decomposition of sugars. The other two peaks of $m / z=108$ and $m / z=123$ appeared at high temperature $\left(300-500{ }^{\circ} \mathrm{C}\right)$ were considered to be the original thermal decomposition peak of urushiol. Acetone powder, which is the acetone insoluble material during extracted urushiol with acetone, also was analyzed by EGA, and the peak position of acetone powder was mostly in agreement with the second EGA peak, that is, there are many sugars contain in the acetone powder.

Figure 2. EGA charts of lacquer.

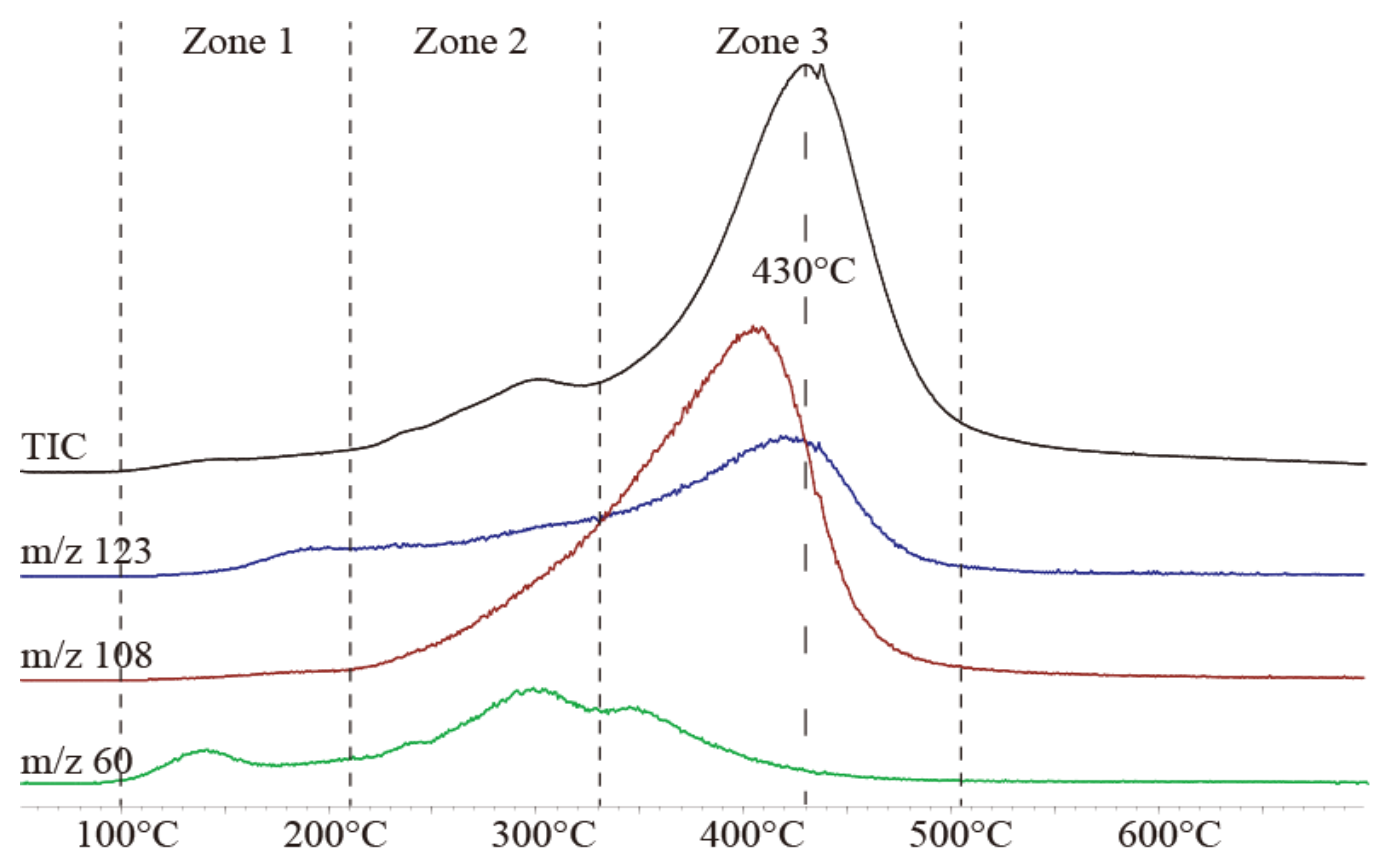

\subsection{Double-Shot Pyrolysis}

Double-shot pyrolysis can be performed using the results of EGA. As volatile and non-volatile compounds can be analyzed separately, simple chromatograms are obtained. Double-shot pyrolysis applies heat to the sample gradually and analyzes the gas generated in only a certain range. This method is very useful for characterization of plastics and rubber. There are two types of Py-GC/MS measurement, direct and derivative methods. As highly polar materials, such as urushiol, tend to adhere to a GC column and decrease the analytical sensitivity, using thermal desorption additives such as tetramethyl-ammonium hydroxide (TMAH), which can be analyzed separately and pyrolyzed with the polymer, can be useful [15-17]. This technique is convenient to remove a plasticizer previously added to a sample or to remove a solvent that remains in very small quantity and is very effective for components with clearly different heat decomposition points. However, this method cannot be used when a sample reacts with the energy of heating. In the case of lacquer sap, various additive admixtures 
such as tung oil, rosin, and tar may be present. The methylation of hydroxyl groups of urushiol is shown in Figure 3. The lacquer film and TMAH were combined in the sample cup and then pyrolyzed at $500{ }^{\circ} \mathrm{C}$.

Figure 3. Methylation reaction of urushiol hydroxyl group with TMAH.<smiles>[R]c1cccc(CCCCC)c1OC</smiles>

\section{Mechanism of Lacquer Drying}

Lacquer is a natural polymer tapped from lacquer trees and used for coating and adhesive materials. Lacquer is dried under specific conditions: over $70 \%$ relative humidity $(\mathrm{RH})$ at room temperature overnight. The mechanism of drying by oxidizing the main lipid component, such as urushiol, laccol, and thitsiol, by laccase has been revealed [18-20]. When the concentration of the lipid monomer is decreased to less than $30 \%$, the unsaturated side-chain autoxidation occurs, and then a very dense network lacquer film is formed [21-23]. Once lacquer sap dries to form a lacquer film, this film is very sturdy and cannot be dissolved in any solvent, as shown in Figure 4. This is a wonderful property for paint, but it has severely impacted its scientific analysis because scientific analysis usually requires dissolution in a solvent.

Figure 4. Image (a) and chemical structure (b) of lacquer polymerization.

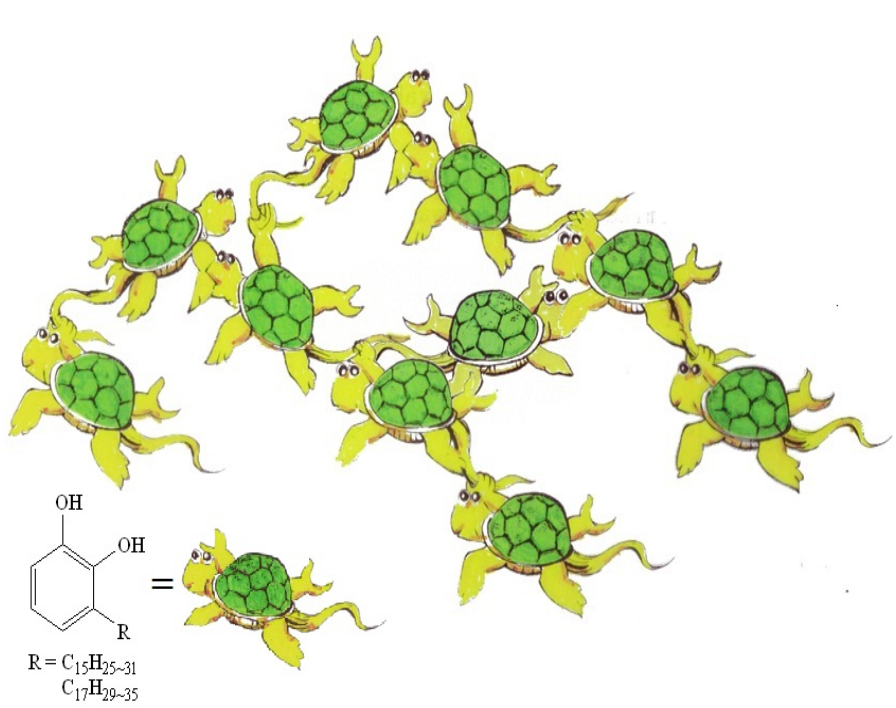

(a)

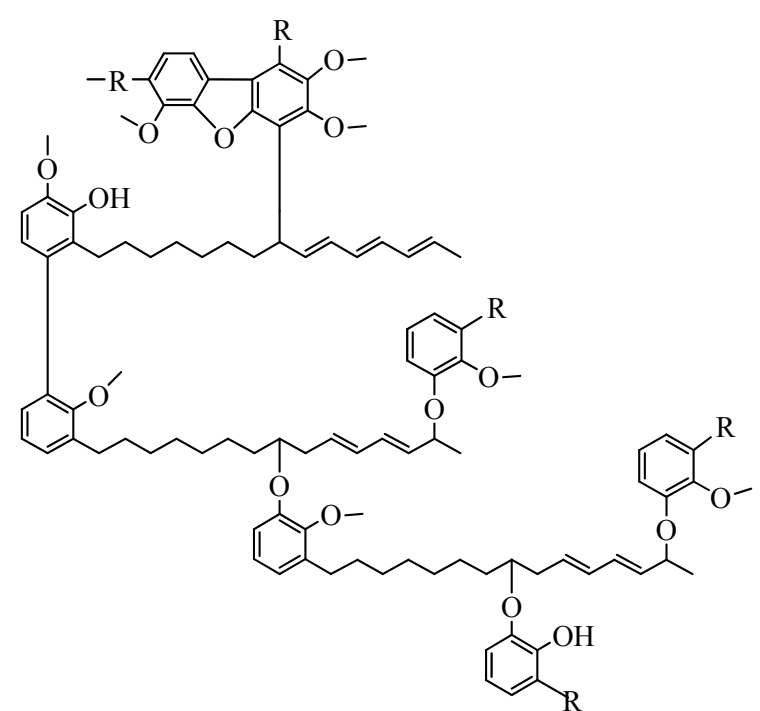

(b) 


\section{Identification of Lacquer Species by Py-GC/MS}

Lacquer film has approximately $6 \mathrm{H}$ pencil hardness, and analysis of such a hard material is difficult. Fourier transform infrared (FT-IR) and solid state nuclear magnetic resonance (NMR) spectroscopy have been employed to analyze it. However, FT-IR cannot distinguish structures similar to that of the lacquer, and also cannot identify various organic and/or inorganic materials that are blended with the lacquer sap [24,25]. Of course, FT-IR also cannot distinguish the species of lacquer tree. The peaks appearing in a solid state NMR are very complex to analyze, and it is difficult to obtain clear results [26]. Therefore, Py-GC/MS is employed to analyze lacquer samples. After being heated to a high temperature, the sample becomes vaporized, the gas products are analyzed, and the sample structure can be inferred. There are three steps in the process. The first is thermal decomposition of the lacquer film, the second is separating the vaporized components of the lacquer, and the third is identified by mass spectrometry. Based on the mass results, the lacquer film structure and the original liquid component are identified.

In order to identify different lacquer tree species and reveal chemical changes during the polymerization process, we have synthesized three kinds of lacquer liquid component derivatives and made films of them. The synthesized and natural lacquer films were analyzed by Py-GC/MS, and the respective characteristics of pyrolysis products were summarized. After assigning each mass chromatogram peak and each mass spectrum, the results showed that the peak at $\mathrm{m} / z=108$ is a characteristic fragment obtained from fragmentation of 3-heptylphenol (C7) for urushiol; 3-nonylphenol (C9) for laccol; 3-heptylphenol (C7), 2-(10-phenyldecyl)phenol (C16), and 3-(10-phenyldecyl)phenol (C16) for thitsiol; while those at $\mathrm{m} / \mathrm{z}=123$ are 3-heptylcatechol (C7) for urushiol; 3-nonylcatechol (C9) for laccol; 3-heptylcatechol (C7), 4-heptylcatechol (C7), 3-(10-phenyldecyl)catechol, and 4-(10-phenyldecyl)catechol for thitsiol, respectively [27,28]. Because the liquid component (urushiol, laccol, and thitsiol) is a catechol structure with two hydroxyl groups $(-\mathrm{OH})$ on a benzene ring, a phenol structure with one hydroxyl group on the benzene ring is usually detected in the Py-GC/MS products (Figure 5a). This is because when lacquer hardens, the hydroxyl group is involved in the polymerization reaction (Figure 4), and the $-\mathrm{OH}$ bond is easily broken during pyrolysis. In general, the thermal decomposition reaction progresses more easily on the phenol structure (Figure 5a) than on the catechol structure (Figure 5b) [29].

The results from the synthesized lacquer films showed that during the laccase-catalyzed polymerization process, nucleus-nucleus $(\mathrm{C}-\mathrm{C})$ and nucleus-side chain $(\mathrm{C}-\mathrm{C}, \mathrm{C}-\mathrm{O}-\mathrm{C})$ coupling occurred first in urushiol derivatives, and subsequently autoxidation of side chain-side chain $(\mathrm{C}-\mathrm{C})$ occurred, like the natural urushiol lacquer [30]. These results were confirmed by Niimura et al. using two-stage Py-GC/MS and X-ray photoelectron spectroscopy [31]. Laccol derivatives showed a polymerization mechanism similar to that of natural laccol lacquer [29,32]. However, in the 3-(10-phenyldecyl)catechol of a thitsiol derivative, the quinone produced by laccase formed an ether bond not with the phenyl group but with a catechol ring, and 3-(10-phenyldecyl)catechol was only polymerized by the laccase catalyst without autoxidation, unlike the natural thitsiol lacquer [33]. In addition, it was also confirmed that neither $\omega$-phenylalkylcatechol nor $\omega$-phenylalkylphenol was present in the natural urushiol or laccol lacquer saps [28,34]. 
Figure 5. Phenol (a) and catechol (b) structures produced by thermal decomposition.

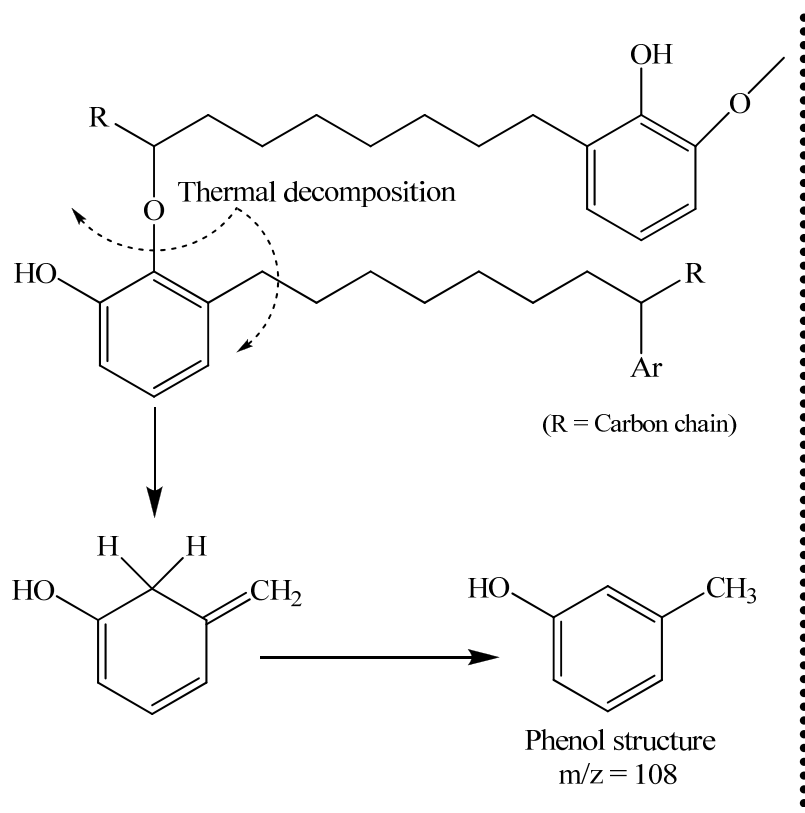

(a)

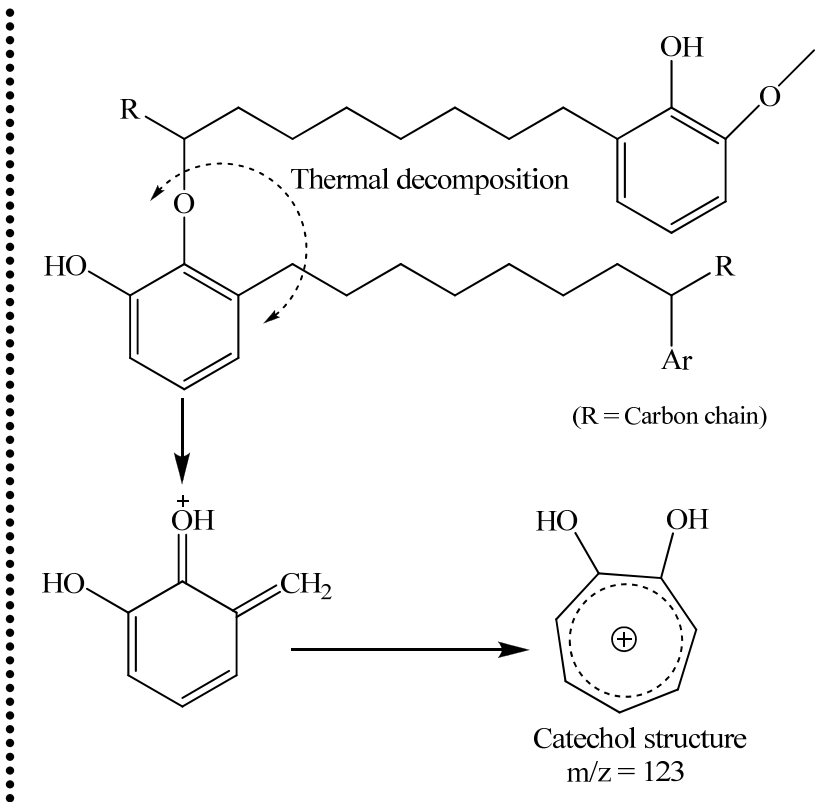

(b)

\section{Application of Py-GC/MS to Ancient Lacquer Wares}

Lacquer has been used as a sophisticated coating material in Asian countries for thousands of years, and it is still used in modern daily life in furniture, decorative objects, architecture, and so on. A red lacquer vertical comb dating to 5500 years ago has been excavated from an early Jomon period in Japan. A Hemudu vermilion lacquered wooden bowl manufactured 7000 years ago was found in China in 1977. Lacquer is inextricably linked with human life, but how ancient people obtained natural lacquer sap and produced lacquer wares is not still clear. Addressing these questions requires scientific analysis. Chiavari and Mazzeo analyzed the paint layers in Chinese archaeological relics by Py-GC/MS in 1999. The results showed that Py-GC/MS offers a rapid means of differentiating between wax and proteinacious binders [35]. Niimura et al. also reported identification of ancient lacquer film by two-stage Py-GC/MS in 1999 [36]. The first pyrolysis at $400{ }^{\circ} \mathrm{C}$ detected fatty acids, and then raising the temperature to $500{ }^{\circ} \mathrm{C}$ detected alkenes, alkanes, alkenylphenols, alkylphenols, alkenylcatechols, and alkylcatechols.

TMAH was usually used as a derivatizing agent in the early pyrolysis method for elucidation of the structure of alkyd, unsaturated polyester, epoxy, and phenol formaldehyde resins [37]. However, as pyrolysis technology advanced, lacquer could be analyzed by Py-GC/MS directly without any derivatization. Due to these advances, Py-GC/MS is widely used to identify the lacquer species of ancient lacquer wares, and the results are very important for conservation and restoration of lacquer wares for historical and cultural purposes. In 2005, Raffaelly et al. reported the analysis of lacquer flakes excavated in an early era necropolis in Mongolia by SEM, FT-IR, X-ray, GC/MS, and Py-GC/MS measurements [38]. The results showed that the Mongolian lacquer wares coating was sap tapped from a Rhus vernicifera lacquer tree.

In order to improve the performance of lacquer or prepare colored lacquer, a binding medium, such as tung oil, linseed oil, animal glue, colophon, plant gum, or inorganic minerals, is usually mixed into 
lacquer sap during the lacquer production process. Py-GC/MS is one of the best methods to identify these additives [39-41]; for example, cinnabar, which is usually used as a red pigment, showed a sharp peak at $m / z=202$ for $\mathrm{Hg}$ in mass spectrometry (Figure 6a, [42]). In the Py-GC/MS measurement, $\mathrm{HgS}$ was broken down into $\mathrm{Hg}$ and $\mathrm{S}$ by heating, and $\mathrm{Hg}$ was detected. Like $\mathrm{HgS}, \mathrm{As}_{2} \mathrm{~S}_{3}$ is usually used as a yellow-green pigment and elementary As was detected at $m / z=74.9$ for $1 \times$ As, $m / z=149.8$ for $2 \times$ As, $m / z=224.7$ for $3 \times$ As, and $m / z=299.6$ for $4 \times$ As in the mass spectrometry of a piece of ancient green lacquerware (Figure $6 \mathrm{~b}[42]$ ).

Figure 6. Mass spectrometry of (a) $\mathrm{Hg}$ and (b) As elements from vermilion and green lacquer wares, respectively.

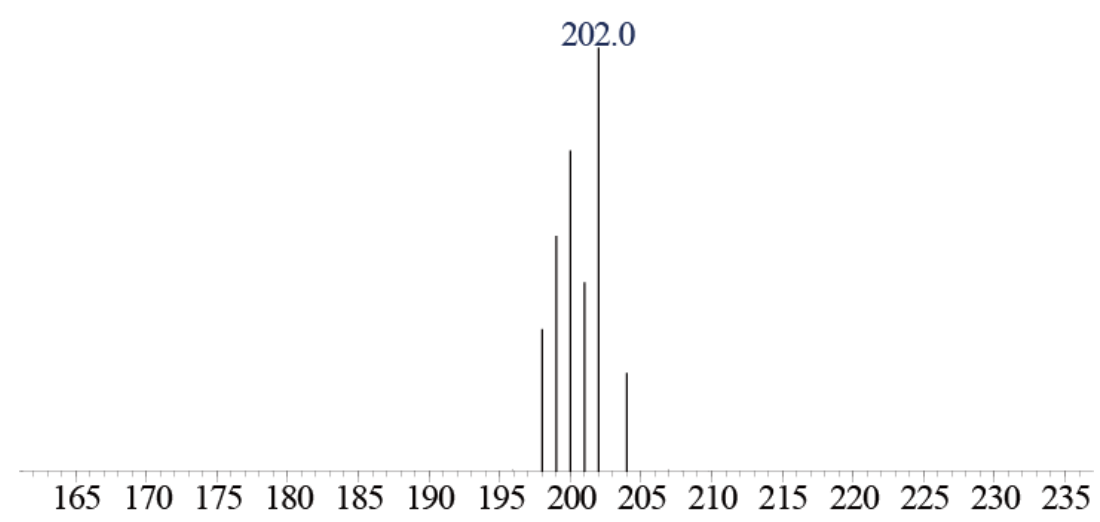

(a)

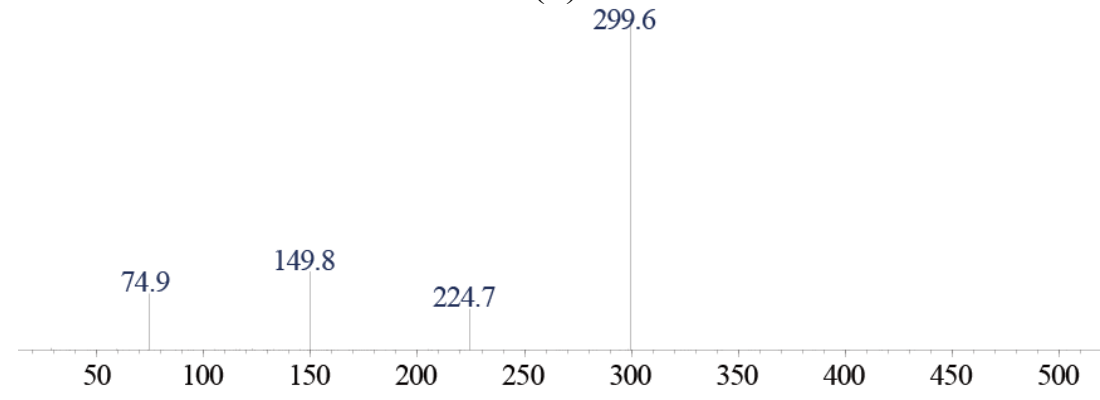

(b)

As described in the introduction section, there are three kinds of lacquer trees in the world, and the main lipid components are different. Py-GC/MS is also used to identify the species of lacquer tree. In general, Chinese lacquer trees belong to the Rhus vernicifera family; however, lacquer trees in the Donglan area of Guangxi Province in China were identified as Rhus succedanea species by analyzing their characteristic pyrolysis products [43]. In the identification of lacquer trees, pyrolysis is an alternative and efficient technique [44]. Furthermore, we applied Py-GC/MS in analysis of an ancient lacquer film that was obtained from the surface of a wooden dish excavated from a site that dates back to the 17-18th century A.D. at Kinenkanmae Iseki (the ruins in the front of the museum) on the Meiji University campus in Tokyo, Japan, a Nanban lacquer film from the 17th century A.D., an old lacquer film obtained from the surface of wooden crafts imported from an Asian country during the 17th-18th century A.D., and Baroque and Rococo lacquer films obtained from the wood surfaces of the Rococo church St. Alto in Altomunster, Munich, Germany. After comparing the results with the characteristic pyrolysis products of urushiol, laccol, and thitsiol, the ancient lacquer film and 
Nanban lacquer film were assigned to Rhus vernicifera, the old lacquerware imported from an Asian country was assigned to Melanorrhoea (Gluta) usitata. However, although they were also called "lacquer," the Baroque and Rococo lacquer films were identified as being made from a natural resin [45]. Meanwhile, the pyrolysis results of the six pieces of lacquer that were obtained from a Ryukyu lacquerware collection belonging to the Urasoe Art Museum of Japan showed that some pieces were made from Rhus vernicifera sap and some were made from Rhus succedanea sap [46]. Furthermore, analysis of a "four-eared" pottery container that was designated an important National Cultural Property from the 16th-17th century A.D. ruins in Kyoto, Japan, by Py-GC/MS showed that the lacquer fragment was Melanorrhoea (Gluta) usitata [47].

The successful application of Py-GC/MS to lacquer and lacquer film makes it possible to analyze and identify, many important cultural heritage lacquer wares that are scattered in museums around the world. The resin and oil components of period lacquer pieces from both Asian and European sources now belonging to the J. Paul Getty Museum were analyzed, and a database is being assembled [48]. Frade et al. analyzed two lacquer shields exported to Portugal from Asia in the 16th century; the results showed that the sample in the Soares dos Reis National Museum was coated with Rhus succedanea lacquer sap and that oil was used as the binding medium, and another sample in a private collection showed characteristic pyrolysis products of Melanorrhoea (Gluta) usitata [49]. A lacquered wooden dish from the Ryukyu Kingdom [50], a lacquer cabinet belonging to the Hofmobiliendepot Möbel Museum Wien in Austria [51], and lacquer objects excavated from a Chu tomb in China [52] were analyzed by pyrolysis. The results showed that both lacquer wares are coated with lacquer sap tapped from Rhus vernicifera lacquer trees, and linseed oil was found to be the binding medium for drying. Recently, Le Ho et al. reported lacquer wares of 18th-19th century Japanese Buddhist altar (Musée Georges-Labit, Toulouse, France) and a Mongolian coated wooden sample from a chariot provided by the Mission archeologique francaise en Mongolie (MAFM) which dated between the 1st century B.C. and the 1st century A.D. [53]. After it was compared with the standard characteristic pyrolysis products, the results showed that the MAFM chariot was coated with lacquer sap from a Rhus vernicifera lacquer tree. We were surprised that the Japanese Buddhist altar was coated with Melanorrhoea (Gluta) usitata lacquer sap, because it implies a commercial relationship between Japan and Southwest Asia. This result also agrees with the material of the "four-eared" pottery container from Kyoto City in Japan [47].

The enzyme-catalyzed polymerization of lacquer sap is also called the lacquer drying and hardening process. As it is very important to investigate the process of functional expression in coating material science, Niimura and Miyakoshi examined the functional expression of Asian lacquer film by Py-GC/MS during the hardening process and found that Asian lacquer develops an extreme hardness and insolubility by accelerating nucleus-side chain $(\mathrm{C}-\mathrm{C}, \mathrm{C}-\mathrm{O}-\mathrm{C})$ and side chain-side chain $(\mathrm{C}-\mathrm{C})$ cross-linkages [54]. Py-GC/MS also was used to confirm the structure of a laccase-catalyzed reaction [55,56]. Recently, on-line micro-ultraviolet pyrolysis GC/MS [57], evolved gas analysis-ion [58], and thermogravimetry-linked scan mass spectrometry [59] were used to analyze ancient lacquer wares, and then the results were compared with standard lacquer films. These improved methods give useful results during the analysis process and demonstrate that Py-GC/MS is a most effective method to characterize natural lacquer films and identify the organic coatings of ancient lacquer wares. 


\section{Conclusions}

Lacquer is a natural coating polymer catalyzed by laccase during drying. Because lacquer sap contains laccase, lacquer is considered self-drying. The special drying mechanism and dihydroxyphenol structure of the lacquer lipid component (urushiol, laccol, or thitsiol) make the lacquer film form a dense network structure that is insoluble in any solvent. Although many existing methods of analysis, such as FT-IR, NMR, and XPS have been used in lacquer film studies, the results were not satisfactory. With progress of the technology, Py-GC/MS became an effective method for analyzing lacquer sap and lacquer film because there are characteristic pyrolysis products that discriminate a lacquer sample and that of other natural resins. After analyzing the structure of the specific pyrolysis products obtained from mass spectrometry, the lacquer tree species and indigenous region can be determined. These results can be used to guide the conservation and restoration of important ancient lacquer wares.

\section{Conflicts of Interest}

The authors declare no conflict of interest.

\section{References}

1. Ishimatsu, S. On a chemical investigation of Japan liquor or urushi. Series-3. Mem. Proc. Manch. Lit. Philos. Soc. 1882, 7, 249-251.

2. Burmester, A. Far eastern lacquers: Classification by pyrolysis mass spectrometry. Archaeometry 1983, 25, 45-58.

3. Shedrinsky, A.M. Application of analysis to problems in art and archaeology: A review. J. Anal. Appl. Pyrolysis 1989, 15, 393-412.

4. Niimura, N.; Miyakoshi, T.; Onodera, J.; Higuchi, T. Thermal degradation of the lacquer film by pyrolysis gas chromatography mass spectrometry. Chem. Soc. Jpn. 1995, 9, 724-729.

5. Niimura, N.; Miyakoshi, T.; Onodera, J.; Higuchi, T. Characterization of Rhus vernicifera and Rhus succedanea lacquer films and their pyrolysis mechanisms studied using two-stage pyrolysis-gas chromatography/mass spectrometry. J. Anal. Appl. Pyrolysis 1996, 37, 199-209.

6. Niimura, N.; Miyakoshi, T.; Onodera, J.; Higuchi, T. Structural studies of Melanorrhoea usitate lacquer film using two-stage pyrolysis/gas chromatography/mass spectrometry. Rapid Commun. Mass Spectrom. 1996, 10, 1719-1724.

7. Wampler, T.P. Pyrolysis, Gas Chromatography; Oxford, PA, USA, 2005; pp. 81-95.

8. Sobeih, K.L.; Baron, M.; Gonzalez-Rodriguez, J. Recent trends and developments in pyrolysis-gas chromatography. J. Chromatogr. A 2008, 1186, 51-66.

9. Tsuge, S.; Ohtani, H.; Watanabe, C. Pyrolysis-GC/MS Data Book of Synthetic Polymers, 1st ed.; Elsevier: Oxford, UK, 2011.

10. Herreraa, M.; Matuschek, G. Fast identification of polymer additives by pyrolysis-gas chromatography/mass spectrometry. J. Anal. Appl. Pyrolysis 2003, 70, 35-42.

11. Arii, T. Complex thermal analysis: Evolved gas analysis-mass spectrometry EGA-MS. Rigaku Janaru 2008, 39, 17-25 (in Japanese). 
12. Arii, T. Evolved gas analysis-mass spectrometry (EGA-MS) using skimmer interface system equipped with pressure control function. J. Mass Spectrom. Soc. Jpn. 2005, 53, 211-216.

13. Tsugoshi, T.; Furukawa, M.; Ohashi, M.; Iida, Y. Comparison of capillary and skimmer interfaces in evolved gas analysis-mass spectrometry (EGA-MS) with regard to impurities in ceramic raw materials. J. Therm. Anal. Calor. 2001, 64, 1127-1132.

14. Matuschek, G.; Kettrup, A.; Prior, A. EGA/MS investigations on the thermal degradation of diammoniumhexachloroplatinate. J. Therm. Anal. Calorim. 1999, 56, 471-477.

15. Urakami, K.; Higashi, A.; Umemoto, K.; Godo, M.; Watanabe, C.; Hashimoto, K. Compositional analysis of copoly(DL-lactic/glycolic acid) (PLGA) by pyrolysis-gas chromatography/mass spectrometry combined with one-step thermally assisted hydrolysis and methylation in the presence of tetramethylammonium hydroxide. Chem. Pharm. Bull. 2001, 49, 203-205.

16. Fukushima, M.; Yamamoto, M.; Komai, T.; Yamamoto, K. Studies of structural alterations of humic acids from conifer bark residue during composting by pyrolysis-gas chromatography/mass spectrometry using tetramethylammonium hydroxide (TMAH-py-GC/MS). J. Anal. Appl. Pyrolysis 2009, 86, 200-206.

17. Araki, H.; Tatarazako, N.; Kishi, K.; Kuroda, K. Evaluation of bioaccumulation potential of 3,4,5-trichloroguaiacol in a zooplankton (Daphnia magna) by pyrolysis-GC/MS in the presence of tetramethylammonium hydroxide (TMAH). J. Anal. Appl. Pyrolysis 2000, 55, 69-80.

18. Oshima, R.; Yamauchi, Y.; Watanabe, C.; Kumanotani, J. Enzymic oxidative coupling of urushiol in sap of the lac tree, Rhus vernicifera. J. Org. Chem. 1985, 50, 2613-2621.

19. Takei, R.; Lu, R.; Miyakoshi, T. Dimer structures and laccase-catalyzed polymerization mechanism of laccol in fresh Rhus succedanea lacquer sap. Int. J. Polym. Anal. Charact. 2013, 18, 1-12.

20. Lu, R.; Kanamori, D.; Miyakoshi, T. Characterization of thitsiol dimer structures from Melanorrhoea usitata with laccase catalyst by NMR spectroscopy. Int. J. Polym. Anal. Charact. 2011, 16, 86-94.

21. Nagase, K.; Kamiya, Y.; Kimura, T.; Hodumi, K.; Miyakoshi, T. The relationship between the change of progress time in the urushi liquid by the enzymic polymerization and the natural drying property occurring under a low humidity environment. Nippon Kagaku Kaishi 2001, 10, 587-593 (in Japanese).

22. Nagase, K.; Kamiya, Y.; Hodumi, K.; Miyakoshi, T. The relationship between the change in urushiol by repetitive "KUROME" of the urushi liquid and natural drying property occurring in a low humidity environment. Nippon Kagaku Kaishi 2002, 3, 377-384 (in Japanese).

23. Nagase, K.; Lu, R.; Miyakoshi, T. Studies on the fast drying hybrid urushi in low humidity environment. Chem. Lett. 2004, 33, 90-91.

24. Kumanotani, J. Super-durable structure of Oriental lacquer films. Polym. Mater. 1988, 59, 278-282 (in Japanese).

25. Kumanotani, J. Urushi (Oriental lacquer) - A natural aesthetic durable and future-promising coating. Prog. Org. Coat. 1995, 26, 163-195.

26. Lambert, J.; Frye, J.; Carriveau, G. The structure of Oriental lacquer by solid state nuclear magnetic resonance spectroscopy. Archaeometry 1991, 33, 87-93.

27. Niimura, N.; Miyakoshi, T. Characterization of natural resin films and identification of ancient coating. J. Mass Spectrom. Soc. Jpn. 2003, 51, 439-457. 
28. Lu, R.; Kamiya, Y.; Miyakoshi, T. Preparation and characterization of Melanorrhoea usitata lacquer film based on pyrolysis-gas chromatography/mass spectrometry. J. Anal. Appl. Pyrolysis 2007, 78, 172-179.

29. Lu, R.; Kamiya, Y.; Wan, Y.-Y.; Honda, T.; Miyakoshi, T. Synthesis of Rhus succedanea lacquer film and analysis by pyrolysis-gas chromatography/mass spectrometry. J. Anal. Appl. Pyrolysis 2007, 78, 117-124.

30. Kamiya, Y.; Niimura, N.; Miyakoshi, T. Evaluation of synthesized lacquer films using pyrolysis-gas chromatography/mass spectrometry. Bull. Chem. Soc. Jpn. 2000, 73, 2621-2626.

31. Niimura, N.; Miyakoshi, T.; Iijima, Y. Characterization of synthesized lacquer analogue films by two-stage pyrolysis gas chromatography/mass spectrometry and X-ray photoelectron spectroscopy. Anal. Sci. 2001, 17 (Suppl.), i155-i158.

32. Kamiya, Y.; Satto, W.; Miyakoshi, T. Synthesis and identification of laccol components from Rhus succedanea lacquer sap. J. Oleo Sci. 2002, 51, 473-483.

33. Lu, R.; Kamiya, Y.; Miyakoshi, T. Characterization of lipid components of Melanorrhoea usitata lacquer sap. Talanta 2007, 71, 1536-1540.

34. Kamiya, Y.; Miyakoshi, T. Synthesis of urushiol components and analysis of urushi sap from Rhus vernicifera. J. Oleo Sci. 2001, 50, 865-874.

35. Chiavari, G.; Mazzeo, R. Characterisation of paint layers in Chinese archaelogical relics by pyrolysis-GC-MS. Chromatographia 1999, 49, 268-272.

36. Niimura, N.; Miyakoshi, T.; Onodera, J.; Higuchi, T. Identification of ancient lacquer film using two-stage pyrolysis-gas chromatography/mass spectrometry. Archaeometry 1999, 41, 137-149.

37. Buzzini, P.; Stoecklein, W. Paints, varnishes, and lacquers. Forensic Sci. 2005, 453-464.

38. Raffaelly, L.; Pons, E.; Lacoudre, N.; Bleton, J.; Duy, S.; Tchapla, A. Characterisation physico-chimique de laques de Mongolie du Ier siecle ap. J.-C. ArcheoSciences 2005, 29, 69-81.

39. Kamiya, Y.; Lu, R.; Kumamoto, T.; Honnda, T.; Miyakoshi, T. Deterioration of surface structure of lacquer films due to ultraviolet irradiation. Surf. Inter. Anal. 2006, 38, 1311-1315.

40. He, L.; Maiqian, N.; Chiavari, G.; Mazzeo, R. Analytical characterization of binding medium used in ancient Chinese artworks by pyrolysis-gas chromatography/mass spectrometry. Microchem. J. 2007, 85, 347-353.

41. Domenech-Carbo, M.T. Novel analytical methods for characterising binding media and protective coatings in artworks. Anal. Chim. Acta 2008, 621, 109-139.

42. Lu, R.; Miyakoshi, T. Meiji University, Kawasaki-shi, Japan. Unpublished work, 2012.

43. Wan, Y.-Y.; Lu, R.; Du, Y.-M.; Honda, T.; Miyakoshi, T. Does Donglan lacquer tree belong to Rhus vernicifera species? Int. J. Biol. Macromol. 2007, 41, 497-503.

44. Frade, J.C.; Ribeiro, I.; Graca, J.; Vasconcelos, T.; Rodrigues, J. Chemotaxonomic application of Py-GC/MS: Identification of lacquer trees. J. Anal. Appl. Pyrolysis 2010, 89, 117-121.

45. Lu, R.; Kamiya, Y.; Miyakoshi, T. Applied analysis of lacquer films based on pyrolysis-gas chromatography/mass spectrometry. Talanta 2006, 70, 370-376.

46. Lu, R.; Ma, X.-M.; Kamiya, Y.; Honda, T.; Kamiya, Y.; Okamoto, A.; Miyakoshi, T. Identification of Ryukyu lacquerware by pyrolysis-gas chromatography/mass spectrometry. J. Anal. Appl. Pyrolysis 2007, 80, 101-110. 
47. Honda, T.; Lu, R.; Kitano, N.; Kamiya, Y.; Miyakoshi, T. Applied analysis and identification of ancient lacquer based on pyrolysis-gas chromatography/mass spectrometry. J. Appl. Polym. Sci. 2010, 118, 897-901.

48. Heginbotham, A.; Khanjian, H.; Rivenc, R.; Schilling, M. A procedure for the efficient and simultaneous analysis of asian and european lacquers in furniture of mixed origin; ICOM Comm. Conserv. 2008, 2, 608-616.

49. Frade, J.C.; Ribeiro, M.I.; Graca, J.; Rodrigues, J. Applying pyrolysis-gas chromatography/mass spectrometry to the identification of Oriental lacquers: Study of two lacquered shields. Anal. Bioanal. Chem. 2009, 395, 2167-2174.

50. Niimura, N. Determination of the type of lacquer on East Asian lacquer ware. Int. J. Mass Spectrom. 2009, 284, 93-94.

51. Pitthard, V.; Wei, S.; Miklin-Kniefacz, S.; Stanek, S.; Griesser, M.; Schreiner, M. Scientific investigations of antique lacquers from a 17th-century Japanese ornamental cabinet. Archaeometry 2010, 52, 1044-1056.

52. Wei, S.; Pintus, V.; Pitthard, V.; Schreiner, M.; Song, G. Analytical characterization of lacquer objects excavated from a Chu tomb in China. J. Archaeol. Sci. 2011, 38, 2667-2674.

53. Le Ho, A.S.; Regert, M.; Marescot, O.; Duhamel, C.; Langlois, J.; Miyakoshi, T.; Genty, C.; Sablier, M. Molecular criteria for discriminating museum Asian lacquerware from different vegetal origins by pyrolysis gas chromatography/mass spectrometry. Anal. Chim. Acta 2012, 710, 9-16.

54. Niimura, N.; Miyakoshi, T. Structural study of oriental lacquer films during the hardening process. Talanta 2006, 70, 146-152.

55. Wan, Y.-Y.; Lu, R.; Akiyama, K.; Miyakoshi, T.; Du, Y.-M. Enzymatic synthesis of bioactive compounds by Rhus laccase from Chinese vernicifera. Sci. China Ser. B Chem. 2007, 50, 179-172.

56. Yoshida, T.; Lu, R.; Han, S.; Hattori, K.; Katsuta, T.; Takada, K.; Sugimoto, K.; Funaoka, M. Laccase-catalyzed polymerization of lignocatechol and affinity on proteins of resulting polymers. J. Polym. Sci. A Polym. Chem. 2009, 47, 824-832.

57. Kamiya, Y.; Taketa, S.; Watanabe, C.; Miyakoshi, T. Characterization of volatile products from raw lacquer film during ultraviolet irradiation using on-line micro ultraviolet pyrolysis-GC/MS. Bunseki Kagaku 2011, 60, 269-274 (in Japanese).

58. Tsukagoshi, M.; Kitahara, Y.; Takahashi, S.; Tsugoshi, T.; Fuji, T. Characterization of Japanese lacquer liquid and films by means of evolved gas analysis-ion attachment mass spectrometry. Anal. Methods 2011, 3, 1943-1947.

59. Niimura, N. Thermogravimetry-linked scan mass spectrometry-Detection of urushiol from an East Asian lacquer film. Therm. Acta 2012, 532, 164-167.

(C) 2014 by the authors; licensee MDPI, Basel, Switzerland. This article is an open access article distributed under the terms and conditions of the Creative Commons Attribution license (http://creativecommons.org/licenses/by/3.0/). 